\title{
BMJ Open Identifying patients with advanced chronic conditions for a progressive palliative care approach: a cross- sectional study of prognostic indicators related to end-of-life trajectories
}

\author{
J Amblàs-Novellas, ${ }^{1,2}$ S A Murray, ${ }^{3} \mathrm{~J}$ Espaulella, ${ }^{1,2} \mathrm{~J}$ C Martori, ${ }^{4} \mathrm{R}$ Oller, ${ }^{4}$ \\ M Martinez-Muñoz, ${ }^{5}$ N Molist, ${ }^{1,2}$ C Blay, ${ }^{2,6}$ X Gómez-Batiste ${ }^{2,7}$
}

To cite: Amblàs-Novellas J, Murray SA, Espaulella J, et al. Identifying patients with advanced chronic conditions for a progressive palliative care approach: a crosssectional study of prognostic indicators related to end-oflife trajectories. BMJ Open 2016;6: 012340.

doi:10.1136/bmjopen-2016012340

- Prepublication history and additional material is available. To view please visit the journal (http://dx.doi.org/ 10.1136/bmjopen-2016012340).

Received 23 April 2016 Revised 6 August 2016 Accepted 11 August 2016

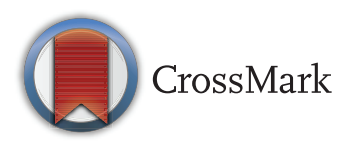

For numbered affiliations see end of article.

Correspondence to Dr Jordi Amblàs-Novellas; jordiamblas@gmail.com

\section{ABSTRACT}

Objectives: 2 innovative concepts have lately been developed to radically improve the care of patients with advanced chronic conditions (PACC): early identification of palliative care (PC) needs and the 3 end-of-life trajectories in chronic illnesses (acute, intermittent and gradual dwindling). It is not clear (1) what indicators work best for this early identification and (2) if specific clinical indicators exist for each of these trajectories. The objectives of this study are to explore these 2 issues.

Setting: 3 primary care services, an acute care hospital, an intermediate care centre and 4 nursing homes in a mixed urban-rural district in Barcelona, Spain.

Participants: 782 patients (61.5\% women) with a positive NECPAL CCOMS-ICO test, indicating they might benefit from a PC approach.

Outcome measures: The characteristics and distribution of the indicators of the NECPAL CCOMSICO tool are analysed with respect to the 3 trajectories and have been arranged by domain (functional, nutritional and cognitive status, emotional problems, geriatric syndromes, social vulnerability and others) and according to their static (severity) and dynamic (progression) properties.

Results: The common indicators associated with early end-of-life identification are functional (44.3\%) and nutritional $(30.7 \%)$ progression, emotional distress $(21.9 \%)$ and geriatric syndromes $(15.7 \%$ delirium, $11.2 \%$ falls). The rest of the indicators showed differences in the associations per illness trajectories $(p<0.05) .48 .2 \%$ of the total cohort was identified as advanced frailty patients with no advanced disease criteria.

Conclusions: Dynamic indicators are present in the 3 trajectories and are especially useful to identify PACC for a progressive PC approach purpose. Most of the other indicators are typically associated with a specific trajectory. These findings can help clinicians improve the identification of patients for a palliative approach.

\section{Strengths and limitations of this study}

- This study innovatively explores the relationship between end-of-life indicators used to identify patients with advanced chronic conditions (PACC) and the three archetypal end-of-life trajectories: acute (typically cancer), intermittent (typically organ failure) and gradual dwindling (typically dementia or frailty).

- Analysing the characteristics of end-of-life indicators allows us to know which indicators most consistently identify patients for palliative care (PC). It also provides data on the characteristics that most commonly occur in each end-of-life trajectory.

- The large number of identified PACC but with no advanced disease criteria reveals that there is a real and not previously well-described cohort of people with advanced frailty and PC needs.

- These concepts are useful for clinical decisionmaking, for policymakers in designing appropriate health services, as well as giving researchers a theoretical framework for future research.

- Study limitations include the heterogeneity in the collection of variables due to the multiple assessments from all healthcare system resources and the number of missing data in some variables.

\section{INTRODUCTION}

Two concepts can be combined to illuminate care provision for patients with advanced chronic conditions (PACC): early identification of patients with palliative care (PC) needs and, second, end-of-life trajectories associated with advanced chronic illnesses. This gives a conceptual framework to understand the different characteristics of patients from their early identification for PC onwards. 


\section{Early identification of patients with PC needs}

The modern approach to the end-of-life divides this into two transitions ${ }^{1}$ (figure 1). The first one, frequently some months or years before death, may constitute the starting of the process of identification of patients with PC needs, due to the appearance and recognition of some indicators or variables which make early identification easier. Throughout the article, we will refer to these patients with advanced chronic diseases and conditions, PC needs and limited life prognosis as "patients with advanced chronic conditions' (PACC). The second transition—or 'the last days or weeks of patient's life' — starts when the terminal decline begins and corresponds to the out-moded paradigm of very late PC provision.

Early identification for PC has shown many benefits: it helps to clarify treatment preferences and goals of care, improves quality of life and symptom control, reduces distress, allows less aggressive care, lower spending, and may even lengthen survival. ${ }^{2-4}$ Thus, to develop anticipatory $\mathrm{PC}^{5}$ becomes crucial during this first transition.

A certain degree of prognostic approach may be used with caution in the care of individual patients, and professionals still have difficulties finding unequivocal prognostic variables. ${ }^{6}$ Prognosis will always imply a degree of uncertainty, ${ }^{7}$ since end-of-life processes are multifactorial and strictly individual at the same time. Besides, the earlier we want to identify these patients, the more difficult it becomes to obtain certain prognostic variables. ${ }^{8}$

Thus, although certain variables are broadly linked with mortality risks, there is no single prognostic indicator that identifies all patients who will die soon. ${ }^{6}$ The classic prognosis approach focused on advanced chronic disease severity criteria has limitations: prognostic disease-centred variables, when used in isolation, have shown low prognostic capacity, ${ }^{9-14}$ particularly for geriatric patients with multiple chronic conditions. ${ }^{6}$ Other general factors have proved to be more reliable end-of-life prognostic indicators than disease-centred variables: $:^{15}$ functional, ${ }^{16-19}$ nutritional ${ }^{20-24}$ and cognitive status; ${ }^{25}{ }^{26}$ emotional problems; ${ }^{27} 28$ geriatric syndromes such as delirium, ${ }^{29}{ }^{30}$ dysphagia, ${ }^{31}$ pressure ulcers ${ }^{32}$ and repetitive falls; ${ }^{33}$ symptoms such as dyspnoea ${ }^{34-36}$ and anxiety ${ }^{37}$ social vulnerability ${ }^{38-41}$ or use of resources. ${ }^{42-44}$

Thus, most screening tools for identification of patients with PC needs ${ }^{45}$-for example, the Prognostic Indicator Guidance of the Gold Standards Framework (PIG-GSF) ${ }^{46}$ the Supportive and Palliative Care Indicators Tool (SPICT), ${ }^{47}$ the RADboud indicators for PAlliative Care needs (RADPAC) ${ }^{48}$ and the NECesidades PALiativas CCOMS-ICO tool (NECPAL CCOMS-ICO tool) ${ }^{49-51}$-have incorporated these general conditions from different domains in different degrees.

The evaluation of these variables-disease specific and these other general factors-has also shown the need for complementing the static status (severity) with an assessment of dynamic progression of decline. ${ }^{8}$

\section{End-of-life trajectories}

In 2003, Lunney et a ${ }^{2}$ described three distinct illness trajectories of functional decline at the end of life (figure 1), illustrating the typical dynamic patterns of a group of patients classified according to their main chronic disease. The first clinical trajectory, typically associated to cancer, features a stable and/or low decline phase broken up by a severe decline in the last few weeks. The second features a gradual decline, with acute episodes usually related to concomitant processes and disease evolution and partial recovery; this trajectory corresponds to patients with advanced organ diseases such as heart, lung, renal and liver failure. Finally, the third trajectory shows a progressive slow-pace decline, typically related to dementia or frail patients.

Later, Murray et a $\tilde{l}^{53}$ highlighted the clinical implications of end-of-life trajectories by presenting trajectories as a framework to help professionals and patients facing the uncertainty of having an advanced chronic condition avoid a prognostic paralysis. First, these trajectories may help clinicians to better plan care to meet their patients' changing needs and help patients and caregivers to cope with their situation. Second, by pointing out that different models of care may be necessary to reflect and tackle patients' different experiences and needs. Third, by graphing dimensional end-of-life trajectories, the different dimensions of need-physical, social, psychological and spiritual-may be identified and addressed.

\section{Hypothesis and objectives}

We hypothesise that there might be a common denominator in the characteristics of some indicators that would allow us to identify PACC at specific time points. On the other hand, distinguishing features may also exist in other indicators that support and develop the conceptual model of end-of-life trajectories.

Learning from the characteristics and evolution of these end-of-life indicators as the basis of the individual situational diagnosis ${ }^{8}$ - understood as the assessment to determine patients' health degree and (or possible) closeness to end-of-life situation (figure 1)—can help clinicians to manage uncertainty and make better clinical decisions, according to patients' values and preferences. ${ }^{54}$ In order to develop further knowledge on these indicators, we analysed the characteristics and distribution of the indicators related to end of life in a cohort of patients identified with the NECPAL CCOMS-ICO tool.

\section{METHODS}

Our methods, as extensively described elsewhere, ${ }^{51}$ are reported according to the Strengthening the Reporting of Observational Studies in Epidemiology (STROBE) recommendations. ${ }^{55}$ This study was formally approved by the ethical research committees of institutions involved in its execution (2010/PREVOsona: P10/65 and EO65). 
Figure 1 Key transitions and the three end-of-life trajectories. Early identification of palliative care needs becomes the starting point for transition 1. Situational diagnosis refers to the evaluation and assessment of patients that allows healthcare professionals determine patients' health degree (A, B, C, D or E) and identify entrance to transition 2 (D) or last days-hours situation, instead (E); this situational diagnosis is indispensable to establish the objectives of care in this progressive care model in a decision-making process shared by professionals, patients and their families.

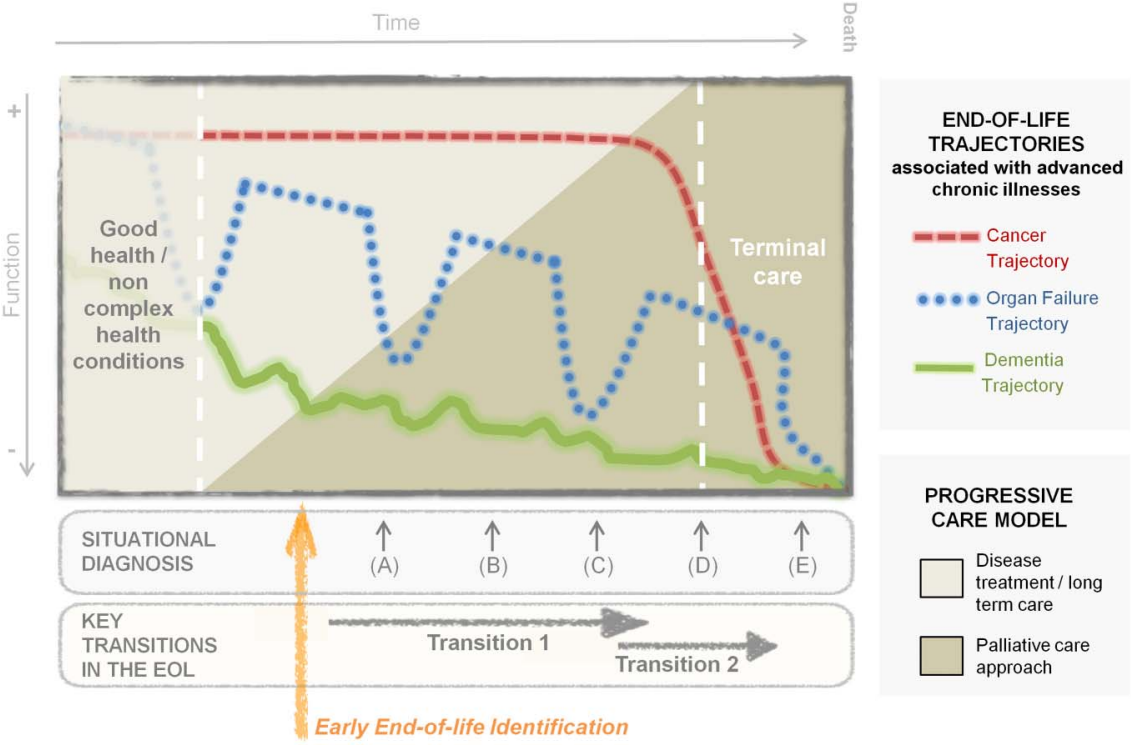

\section{Study design and setting}

A cross-sectional study of patients identified in a previous population-based study was conducted. ${ }^{51}$ The study was conducted in the Spanish district of Osona, Barcelona, a mixed urban-rural district with a population of 156087 residents, $21.4 \%$ of whom are aged $>65$ years, with an annual mortality rate of 8.81 per 1000 inhabitants. Three selected primary care services and an acute care hospital, an intermediate care centre and four nursing homes serving these primary care services agreed to participate.

\section{Eligibility criteria and participant selection}

Case selection was undertaken from November 2010 to October 2011. There were no exclusion criteria. Patient recruitment was made using the NECPAL CCOMS-ICO tool through the healthcare records and by interviews with healthcare professionals (doctors and nurses). 'NECPAL positive $(+)$ ' patients were defined as being surprise-question $^{56}$ answer 'no' ("I would not be surprised if this patient were to die in the next 12 months") and having at least one subsequent positive category: (1) category 1: choice, request or need of PC approach (has the patient or the main caregiver requested palliative/ comfort treatments exclusively or suggests limitation of therapeutic effort? Healthcare professionals consider that the patient requires palliative care or palliative treatment at this moment?); (2) category 2: general clinical prognostic indicators of severity and progression, including comorbidity and resource use (table 1) or (3) category 3: disease-specific prognostic indicators (table 2).

\section{Variables and sources of information}

In the selected cohort, we evaluated the indicators included in the NECPAL CCOMS-ICO tool, which were retrieved, if available, from patient's clinical records by the investigator team or by clinical judgement after interviewing healthcare professionals (including clinical variables and need, demand and choice requests). In order to reduce systematic error, all definitions, procedures-including data collection-and measures were standardised and followed according to the study operations manual.

Indicators were arranged by domain (functional, nutritional and cognitive status, emotional problems, geriatric syndromes, social vulnerability and others) and according to their static (severity) and dynamic (progression) characteristics, for patients in each of the three end-of-life trajectories associated with advanced chronic illnesses.

\section{Indicators and diseases}

We evaluated the distribution of the indicators by classifying persons according to the presence of severity and/ or progression criteria of the main disease (cancer, chronic pulmonary disease, chronic heart disease, serious chronic liver disease, serious chronic renal disease, chronic neurological diseases and dementia). We refer to the group of patients identified as being NECPAL (+) without severity and/or disease progression criteria as 'advanced frailty patients without advanced disease criteria'.

\section{Indicators and end-of-life trajectories}

We organised the illnesses according to the described end-of-life trajectories: cancer, organ failure (including lung, heart, hepatic and renal disease) and dementia. As for neurologic diseases, we put together primary neurodegenerative/Alzheimer and neurodegenerative diseases such as Parkinson and amyotrophic lateral sclerosis for easier analysis purposes, given that their clinical evolution tends to be similar to dementia.

\section{Statistical methods}

Characteristics by domain were reported as averages with SDs for continuous variables (Barthel, Charlson, 
Table 1 Category 2 of the NECPAL CCOMS-ICO tool: general indicators of severity and progression

\begin{tabular}{|c|c|c|}
\hline Domain & Severity & Progression (in the last 6 months) \\
\hline Functional markers & $\begin{array}{l}\text { Serious established functional dependence } \\
(\text { Barthel Score }<25, E C O G>2 \text { or Karnofsky Score } \\
<50 \%)\end{array}$ & $\begin{array}{l}\text { Loss of two or more ADLs even though there is } \\
\text { adequate therapeutic intervention or clinical } \\
\text { perception of functional decline (sustained, } \\
\text { intense/severe, progressive, irreversible) not } \\
\text { related to concurrent conditions }\end{array}$ \\
\hline Nutritional markers & $\begin{array}{l}\text { rum albumin }<2.5 \mathrm{~g} / \mathrm{dL}, \text { not related to acute } \\
\text { sodes of unbalance }\end{array}$ & $\begin{array}{l}\text { Weight loss }>10 \% \text { or clinical perception of } \\
\text { nutritional decline (sustained, intense/severe, } \\
\text { progressive, irreversible) not related to concurrent } \\
\text { conditions }\end{array}$ \\
\hline Cognitive & $\begin{array}{l}\text { Unable to dress, wash or eat without assistance } \\
\text { (GDS/FAST 6c), urinary and faecal incontinence } \\
\text { (GDS/FAST 6d-e) or unable to communicate } \\
\text { meaningfully-six or less intelligible words (GDS/ } \\
\text { FAST 7) }\end{array}$ & $\begin{array}{l}\text { Loss of two or more ADLs in the last } 6 \text { months, } \\
\text { despite adequate therapeutic intervention } \\
\text { (invaluable in hyperacute situation due to } \\
\text { concurrent processes) or difficulty swallowing, or } \\
\text { denial to eat, in patients who will not receive } \\
\text { enteral or parenteral nutrition }\end{array}$ \\
\hline Emotional & \multicolumn{2}{|c|}{$\begin{array}{l}\text { Presence of emotional distress with psychological symptoms (sustained, intense/severe, progressive) } \\
\text { not related to acute concurrent conditions }\end{array}$} \\
\hline $\begin{array}{l}\text { Geriatric syndromes } \\
\text { (in the last } 6 \text { months) }\end{array}$ & \multirow{3}{*}{\multicolumn{2}{|c|}{$\begin{array}{l}\text { Persistent pressure ulcers (stages III-IV), recurrent infections }(>1) \text {, delirium, persistent dysphagia, falls } \\
(>2) \\
\text { Charlson Index } \\
\text { Two or more urgent (unplanned) hospital (or skilled nursing facilities) admissions due to chronic } \\
\text { disease in the last year } \\
\text { Need of complex/intense continuing care, either at an institution or at home }\end{array}$}} \\
\hline Comorbidity & & \\
\hline $\begin{array}{l}\text { Additional factors on } \\
\text { use of resources }\end{array}$ & & \\
\hline
\end{tabular}

ADL, activities of daily living; ECOG, Eastern Cooperative Oncology Group; GDS/FAST, Global Deterioration Scale/Functional Assessment Staging.

unplanned admissions and age) or percentages for the categorical variables. All indicators were calculated for the entire sample and for each four categories of patients: cancer, organ failure, dementia/chronic neurological diseases and advanced frailty. We compared the proportions among the four groups using $\chi^{2}$ test for categorical variables. Differences for non-categorical variables were assessed using ANOVA tests.

Analyses were performed with the Statistical Package for Social Sciences (SPSS), V.21.0. A two-sided $\mathrm{p}$ value $<0.05$ was considered to indicate statistical significance.

\section{RESULTS}

\section{Participants}

A total number of 782 NECPAL positive $(+)$ patients (38.5\% men; $61.5 \%$ women; mean age: 80.89$)$ were recruited from different levels of the health system: 523 $(66.9 \%)$ residents in the community, $154(19.7 \%)$ in nursing homes, $55(7 \%)$ at the intermediate care centre and $50(6.4 \%)$ at the acute care hospital; this distribution of patients among the diverse settings is representative of the population prevalence of these patients. ${ }^{51}$ All participants were allocated to one trajectory presented severity and progression criteria for two concomitant organs. The online supplementary appendix shows the results for each individual disease.

\section{Main results}

Functional progression ( $31.5 \%$ loss $\geq 2$ activities of daily living (ADLs), 44.3\% clinical perception) and nutritional criteria ( particularly clinical perception, $30.7 \%$ ) were the indicators most constantly associated with end-of-life identification in all patients (table 3). For the patients with cancer, organ failure and advanced frailty, we could not determine if there were cognitive progression criteria (na), since this feature was only evaluated as a criterion for advanced dementia. Emotional distress $(21.9 \%)$ and some geriatric syndromes $(11.2 \%$ falls and $15.7 \%$ delirium) were also present, but less frequently and without statistically significant differences among the four groups. Generally, families perceived more palliative needs than the patients and professionals.

The functional severity criteria, cognitive severity criteria, some geriatric syndromes such as decubitus ulcers, dysphagia and repetition infections, comorbidity, use of resources, election criteria, demand and need of $\mathrm{PC}$ and age and gender showed statistically significant differences in the classification per trajectories performed.

- Patients with advanced cancer rarely presented with functional severity criteria $(4.5 \%)$. For these patients, the presence of nutritional progression criteria was more common than in the other groups (clinical perception: $63.2 \%$ ). There was a high need of complex care $(35.1 \%)$, as well as demand and need of PC from the patients $(17.1 \%)$, relatives $(39.5 \%)$ and professionals $(47.4 \%)$.

- Patients with advanced organ disease-all had main disease severity and progression criteria-presented less parameters of general severity and progression than the rest of trajectories and a lower percentage of 
Table 2 Category 3 of the NECPAL CCOMS-ICO tool: disease-specific indicators

Cancer (one single criterion)

Chronic pulmonary disease (two or more criteria)

Chronic heart disease (two or more criteria)

Serious chronic liver disease (one single criterion)

Serious chronic renal disease (one single criterion)

Chronic neurological diseases (1): CVA (one single criterion)

Chronic neurological diseases (2): motor neuron diseases, multiple sclerosis and Parkinson (two or more criteria)

Dementia (two or more of the following criteria)
- Confirmed diagnosis of metastatic cancer who present low response or contraindication of specific treatment, progressive outbreak during treatment or metastatic affectation of vital organs

- Significant functional deterioration (palliative performance status $<50 \%)$

- Persistent, troublesome symptoms, despite optimal treatment of underlying condition(s)

- Breathlessness at rest or on minimal exertion between exacerbations

- Difficult physical or psychological symptoms despite optimal tolerated therapy

- FEV $1<30 \%$ or criteria of restricted severe deficit: FVC $<40 \% /$ $\mathrm{DLCO}<40 \%$

- Accomplishment of oxygen therapy at home criteria

- Recurrent hospital admissions (>3 admissions in 12 months due to exacerbations)

- Heart failure NYHA stage III or IV, severe valve disease or inoperable coronary artery disease

- Shortness of breath at rest or minimal exertion

- Difficult physical or psychological symptoms despite optimal tolerated therapy

- Ejection fraction severely affected $(<30 \%)$ or severe pulmonary hypertension $(>60 \mathrm{~mm} \mathrm{Hg})$

- Renal failure (GFR $<30 \mathrm{~L} / \mathrm{min}$ )

- Repeated hospital admissions with symptoms of heart failure/ ischaemic heart disease ( $>3$ last year)

- Advanced cirrhosis: stage Child C, MELD-Na Score $>30$ or with one or more of the following medical complications: diuretic-resistant ascites, hepatorenal syndrome or upper gastrointestinal bleeding due to portal hypertension with failed response to treatment

- Hepatocellular carcinoma: present, in stage C or D (BCLC)

- Serious renal failures (GFR $<15$ ) in patients to whom substitutive treatment or transplant is contraindicated

- During acute and subacute phases ( $<3$ months poststroke): persistent vegetative or minimal conscious state $>3$ days

- During the chronic phase ( $>3$ months poststroke): repeated medical complications (aspiration pneumonia, pyelonephritis, recurrent febrile episodes, pressure ulcers stages 3-4 or dementia with severe criteria poststroke)

- Progressive deterioration in physical and/or cognitive function despite optimal therapy

- Complex and difficult symptoms

- Speech problems with increasing difficulty communicating

- Progressive dysphagia

- Recurrent aspiration pneumonia, breathless or respiratory failure

- Severity criteria: GDS/FAST 6c or more.

- Progression criteria: loss of two or more ADLs in the last 6 months, despite adequate therapeutic intervention or difficulty swallowing, or denial to eat, in patients who will not receive enteral or parenteral nutrition

- Use of resources criteria: multiple admissions (>3 in 12 months, due to concurrent processes-aspiration pneumonia, pyelonephritis, sepsis, etc-that cause functional and/or cognitive decline)

ADL, activities of daily living; BCLC, Barcelona clinic liver cancer; CVA, cerebrovascular accident; DLCO, diffusing capacity of the lung for carbon monoxide; FEV1, forced expiratory volume in $1 \mathrm{~s}$; FVC, forced vital capacity; GFR, glomerular filtration rate; NYHA, New York Heart Association. 


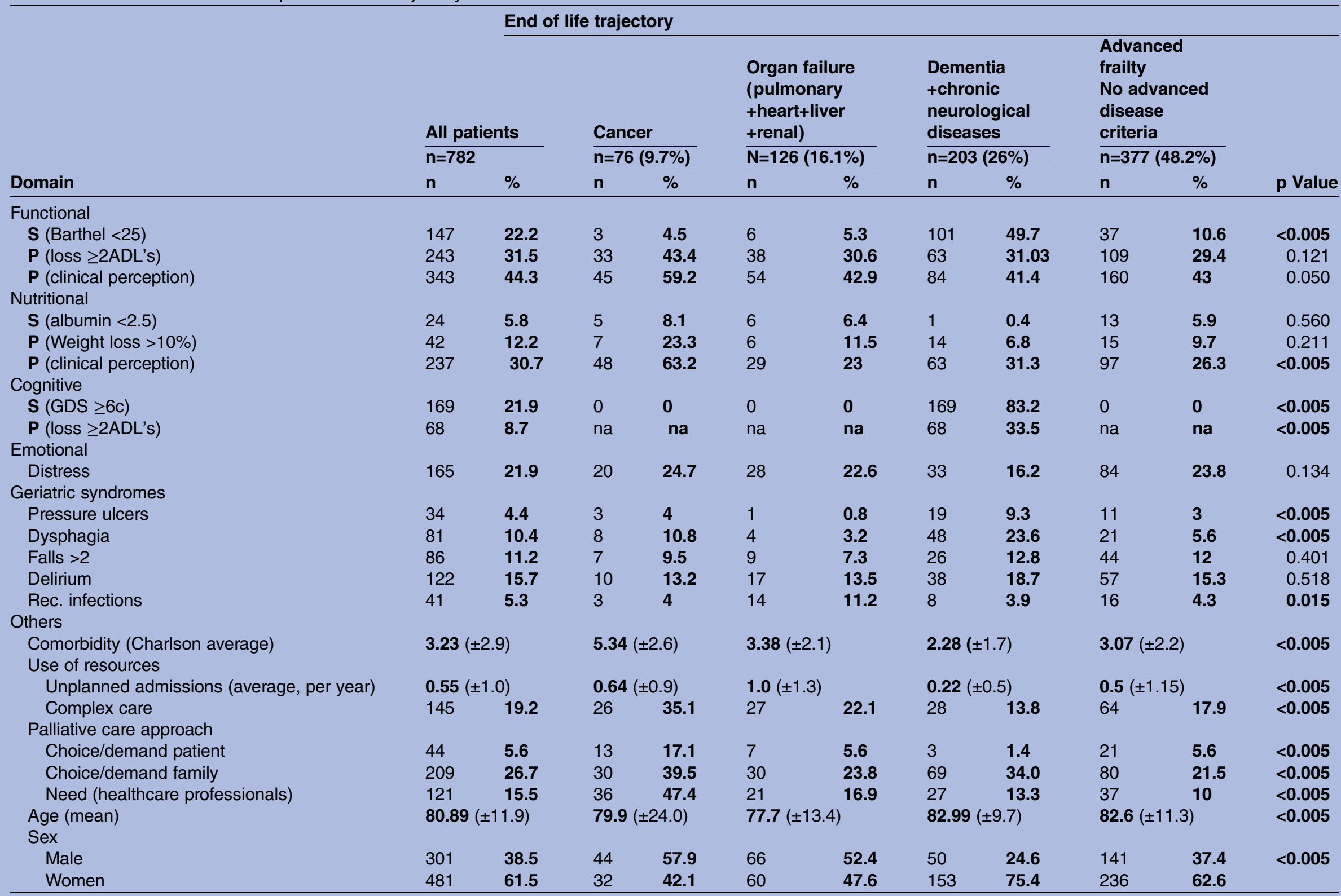

$\%$, Percentage of patients with the presence of the analysed variable with respect to the total of patients (once missing data excluded).

$p$ Values: obtained from comparative analysis among the four groups described: cancer, organ failure, dementia/chronic neurological diseases in advanced frailty.

$\mathrm{ADL}$, activities of daily living; $\mathrm{n}$, number of valid patients for evaluation of variable; na, not applicable; $\mathrm{P}$, progression criteria; $\mathrm{S}$, severity criteria. 
geriatric syndromes. In contrast, they presented a larger percentage of systemic infections $(11.2 \%)$ and more unplanned admissions than the other groups.

- Patients with advanced dementia and those with chronic neurological diseases presented severity criteria, functional $(49.7 \%)$ and cognitive $(83.2 \%)$, and geriatric syndromes: ulcers $(9.3 \%)$, persistent dysphagia $(23.6 \%)$, repetitive falls $(12.8 \%)$ and delirium $(18.7 \%)$. These patients presented less need of resources than the other groups, and there was a low perception of palliative needs among the professionals $(13.3 \%)$ compared to relatives $(34 \%)$.

- $48.2 \%$ of the whole NECPAL $(+)$ patients did not present severity and progression criteria for any chronic disease. In comparison with the other trajectories, no indicator in this group ('advanced frailty patients with no advanced disease criteria') was especially prevalent or relatively infrequent: for instance, these patients present more functional severity criteria $(10.6 \%)$ than patients with cancer $(4.5 \%)$ and patients with organ failure $(5.3 \%)$, but lower than patients with dementia (49.7\%); they present less nutritional progression criteria $(9.7 \%)$ than patients with cancer $(23.3 \%)$ and patients with organ failure $(11.5 \%)$, but more than patients with dementia $(6.8 \%)$ or they have more comorbidities (Charlson: 3.07) than patients with dementia (2.28), but less than patients with cancer (5.34) and patients with organ failure (3.38). Globally, professionals had low perceptions that these patients had palliative needs.

\section{DISCUSSION}

\section{Key results}

Dynamic indicators are more discriminating than static ones to identify PACC. ${ }^{19}$ Functional and nutritional progression criteria (also cognitive progression could be included if there is delirium $)^{57}$ are also important, mainly regarding functional loss. ${ }^{58}{ }^{59}$ This fact is supported by the literature, given the evidence that changing variables have been shown to have better prognostic ability than those variables that remain stable. ${ }^{19} 5859$ Also emotional distress and some geriatric syndromes, though less significantly, have been shown to be useful indicators for early identification.

Beyond the described parameters, we consider that there are no unique and specific indicators to reliably identify PACC, since only a low percentage of patients present most of them. This fact has two implications: (1) early identification of PACC requires a multidimensional evaluation including a wide range of indicators and (2) the different characteristics of these indicators in the diverse groups (cancer, organ disease and dementia/ advanced neurologic disease) support the conceptual model of end-of-life trajectories. This model seems to be consistent beyond the described functional dimension: in many of the other dimensions (nutritional, cognitive, geriatric syndromes and use of resources), the behaviour is also different among the groups.
Regarding the differences of the variables in the three end-of-life trajectories, the low prevalence of patients with advanced cancer and functional severity criteria is remarkable; this could be due to a faster decline of these patients in the second transition-if we assume that most patients of this cohort were stable ${ }^{60-62}$ although it could also be due to a selection bias on the part of recruitment process. The impact of undernourishment as an important marker of end of life in patients with cancer is also consistent with the literature. $^{63-66}$ For patients with advanced organ diseases, there are more unplanned admissions, probably because of episodes of acute failure or infections, in keeping with the trajectory classically described cohort. ${ }^{44} 52$ 67-74 As for patients with dementia or with other neurological diseases the criteria of disease severity (frequently based on the functional repercussions of the severity) determine the identification of the end-of-life situation. ${ }^{75} 76$ This fact, together with the presence of multiple geriatric syndromes, can help professionals in this process of identification. ${ }^{77}$ The slow and progressive process of decline determines less use of resources and, probably, less perception of PC needs from the professionals, in contrast to the relatives' view. This analysis endorses the conceptual approach of typical trajectories of decline in advanced chronic illnesses.

However, with mutimorbidity the norm at the end of life, patients may embrace one or more trajectories. ${ }^{78} 79$ This resulted in an extremely heterogeneous behaviour of the variables over time among different patients.

It was remarkable that in a particularly disease-centred clinical context, practically half of the cohort did not meet advanced disease criteria ('advanced frailty patients with no advanced disease criteria'), but were identified as persons with advanced chronic conditions and PC needs at the same time (NECPAL+); it is estimated that $40 \%$ of deaths occur in frail older people who have no main overriding diagnosis. ${ }^{80}$ This is relevant because it suggests that for early identification for PC it is essential to look beyond disease-centred variables and that multiple general indicators in different domains need to be considered. ${ }^{81}$ Given that frailty is the most prevalent condition as people approach death, ${ }^{82}$ a rational clinical approach to these patients would be to consider frailty not as an independent entity defining only one of the end-of-life trajectories, but as a quantitative measurement system to determine the reserve level of the patient. Such reserve would act as the basis for a 'situational diagnosis'. Analysis shows that most variables are present in the end-of-life trajectories, although they behave differently. It may be that with frail patients, the other non-physical trajectories of need may be important to monitor clinically, as they may show more dynamic needs for care. ${ }^{83}$ More research will be needed to substantiate this claim.

Finally, patients with cancer and patients without cancer present physical decline and significant psychosocial difficulties, and all these patients could benefit 
from a PC approach. However, healthcare professionals currently identify less patients for a palliative approach for the non-cancer group. ${ }^{84}$ This might be because the end-of-life trajectory is less predictable for these patients, but this should not stop identifying these patients according to these indicators, rather than professionals having a prognostic paralysis. ${ }^{85}$

\section{Strengths and limitations}

The study was carried out with $100 \%$ of participation from healthcare professionals and settings invited. A standardised case identification methodology was followed in all settings, and a high level of commitment from all participants was gained.

The study has limitations. Since this study was based on health professionals' assessment and routine data, patients' perspectives were not included. Availability of quantitative data in clinical charts may have affected description of patients' characteristics. The study results may have also been affected by the ageing population and strong influence of geriatric care in the area, as well as by the length of the study window. Additionally, a problem of over identification with the tool cannot be dismissed, due to the high number of 'advanced frailty patients with no advanced disease criteria'. We are currently monitoring the mortality of this cohort to confirm or reject this hypothesis.

There was a significant number of missing nutritional indicators requiring an objective measure $(47.2 \%$ due to albumin or $56 \%$ due to weight loss) $3 / 4$ see online supplementary appendix. This fact emphasises some discordance between the importance of measuring the nutritional state according to scientific evidence $\mathrm{e}^{20-23}$ and the real clinical practice; we wonder whether using other parameters in the evaluation of undernourishment such as body mass index or mini nutritional assessment ${ }^{86}$ results would be indicated. Some of the indicators described in the background section, such as social vulnerability or symptoms, were not included in the NECPAL CCOMS-ICO tool. Thus, these could not be assessed in the study; similarly, the progression criteria for dementia could only be assessed for patients with severity criteria of dementia.

The proposal of grouping neurologic diseases including neurodegenerative diseases such as Parkinson and amyotrophic lateral sclerosis with the group of primary neurodegenerative/Alzheimer is arguable; however, it might have not effected final results, given the low number of patients $(n=31,4 \%$ of the total cohort).

\section{Generalisability and future trends}

More studies are needed to corroborate these data. However, the results described are a useful basis for future research on the early identification of PACC for integrated PC. Suggested topics to be developed include

- The cohort corresponds to persons identified a priori as PACC and likely to die in the foreseeable future. It will be necessary, however, to analyse the behaviour of these variables in relation to mortality. We are currently monitoring the cohort at 24 months.
- Given the large prevalence of advanced frailty patients, new frameworks ${ }^{8}$ and tools $^{87}$ based on knowledge on geriatrics, primary care and PC are indicated. In fact, these three areas already share methods regarding care process: ${ }^{88}$ team work, multidimensional assessment, patient-centred care, psychosocial and caregivers support. More shared research between these specialties and public health will best take this agenda forward together.

- The conceptual link between the need of multidimensional evaluation of PACC and the high prevalence of advanced frailty patients with no advanced disease criteria can be found in the evaluation of the level of reserve of these patients. Frailty indices, ${ }^{89-93}$ already proved to have a strong association with mortality, may become the gold standard for situational diagnosis, since they allow to quantify people's health reserves from a universal and objective point of view.

\section{CONCLUSIONS}

Learning from the behaviour of end-of-life indicators helps clinicians deal with the clinical complexity and innate prognostic uncertainties of this group of patients.

There are indicators of PC needs common to all types of trajectories, and others associated with specific trajectories: dynamic variables most consistently identify PACC and PC needs, regardless of the patient's end-of-life trajectory. Additionally, the analysis of the other indicators allows us to develop useful knowledge relating to how people die in different ways. To explore in detail the characteristics of the indicators in these patients will help to provide them with patient-centred care.

Almost half of the cohort, although identified as PACC, did not have severe or progression advanced disease. This fact is particularly relevant and highlights the need for more research, probably by using new measuring systems for frailty, and the need of alternative conceptual models, probably by defining new end-of-life trajectories, in order to provide better end-of-life care to this great number of people.

\section{Author affiliations}

${ }^{1}$ Geriatric and Palliative Care Department, Hospital Universitari de la Santa Creu/Hospital Universitari de Vic, Barcelona, Spain

${ }^{2}$ Department of Palliative Care, University of Vic, Barcelona, Spain

${ }^{3}$ St Columba's Hospice Chair of Primary Palliative Care, Primary Palliative Care Research Group, The Usher Institute, University of Edinburgh, Edinburgh, UK ${ }^{4}$ Data Analysis and Modeling Research Group, Department of Economics and Business, University of Vic, Barcelona, Spain

${ }^{5}$ Unit of Research Management, Catalan Institute of Oncology, Barcelona, Spain

${ }^{6}$ Programme for the Prevention and Care of Patients with Chronic Conditions, Department of Health, Government of Catalonia, Barcelona, Spain

${ }^{7}$ The Qualy Observatory, WHO Collaborating Centre for Palliative Care Public Health Programs (WHOCC), Catalan Institute of Oncology, Barcelona, Spain

Twitter Follow Jordi Amblàs-Novellas at @jordiamblas

Acknowledgements The authors thank Ms Sara Ela for her support in reviewing and editing the manuscript. All authors revised, edited and approved the final version of the manuscript to be published. 
Contributors JA-N conceptualised and designed the study. MM-M involved in data collection. JCM and OR performed the statistical analysis. JA-N wrote the draft of the manuscript. SAM, MM-M, JE, NM, CB and XG-B contributed to data analysis and interpretation of the findings, reviewed and approved the final manuscript. All authors meet conditions of the International Committee of Medical Journal Editors regarding authorship.

Funding JA-N has received research grants from Consultori Bayés for the $\mathrm{PhD}$ research project 'The advanced frailty as a basis for identifying end-of-life situation and decision-making'; there are no other relationships or activities that could appear to have influenced the submitted work.

Competing interests None declared

Ethics approval 2010/PREVOsona: P10/65 and E065.

Provenance and peer review Not commissioned; externally peer reviewed.

Data sharing statement Additional data are available in the online supplementary appendices. Technical online supplementary appendix and data set are available from the corresponding author on request.

Open Access This is an Open Access article distributed in accordance with the Creative Commons Attribution Non Commercial (CC BY-NC 4.0) license, which permits others to distribute, remix, adapt, build upon this work noncommercially, and license their derivative works on different terms, provided the original work is properly cited and the use is non-commercial. See: http:// creativecommons.org/licenses/by-nc/4.0/

\section{REFERENCES}

1. Boyd K, Murray SA. Recognising and managing key transitions in end of life care. BMJ 2010;341:c4863.

2. Temel JS, Greer JA, Muzikansky A, et al. Early palliative care for patients with metastatic non-small-cell lung cancer. N Engl J Med 2010;363:733-42.

3. Parikh RB, Kirch RA, Smith TJ, et al. Early specialty palliative caretranslating data in oncology into practice. N Engl J Med 2013;369:2347-51.

4. Howie L, Peppercorn J. Early palliative care in cancer treatment: rationale, evidence and clinical implications. Ther Adv Med Oncol 2013;5:318-23

5. Thoonsen B, Vissers $\mathrm{K}$, Verhagen $\mathrm{S}$, et al. Training general practitioners in early identification and anticipatory palliative care planning: a randomized controlled trial. BMC Fam Pract 2015;16:126.

6. Amblàs-Novellas J, Espaulella J, Rexach L, et al. Frailty, severity, progression and shared decision-making: a pragmatic framework for the challenge of clinical complexity at the end of life. Eur Geriatr Med 2015;6:189-94

7. Yourman LC, Lee SJ, Schonberg MA, et al. Prognostic indices for older adults: a systematic review. JAMA 2012;307:182-92.

8. Smith AK, White DB, Arnold RM. Uncertainty-the other side of prognosis. N Engl J Med 2013;368:2448-50.

9. Knaus WA, Harrell FE, Lynn J, et al. The SUPPORT prognostic model: objective estimates of survival for seriously ill hospitalized adults. Ann Intern Med 1995;122:191-203.

10. Lee DS, Austin PC, Rouleau JL, et al. Predicting mortality among patients hospitalized for heart failure: derivation and validation of a clinical model. JAMA 2003;290:2581-7.

11. Gardiner C, Gott M, Small N, et al. Living with advanced chronic obstructive pulmonary disease: patients concerns regarding death and dying. Palliat Med 2009;23:691-7.

12. Altman DG, Vergouwe $Y$, Royston $P$, et al. Prognosis and prognostic research: validating a prognostic model. BMJ 2009;338:b605.

13. Senni M, Parrella $P$, De Maria $R$, et al. Predicting heart failure outcome from cardiac and comorbid conditions: The 3C-HF score. Int J Cardiol 2013;163:206-11.

14. Scarpi E, Maltoni M, Miceli R, et al. Survival prediction for terminally ill cancer patients: revision of the palliative prognostic score with incorporation of delirium. Oncologist 2011:16:1793-9.

15. Thomas JM, Cooney LM, Fried TR. Systematic review: health-related characteristics of elderly hospitalized adults and nursing home residents associated with short-term mortality. J Am Geriatr Soc 2013;61:902-11.

16. Dent $\mathrm{E}$, Chapman I, Howell $\mathrm{S}$, et al. Frailty and functional decline indices predict poor outcomes in hospitalised older people. Age Ageing 2014;43:477-84

17. Millán-Calenti JC, Tubío J, Pita-Fernández S, et al. Prevalence of functional disability in activities of daily living (ADL), instrumental activities of daily living (IADL) and associated factors, as predictors of morbidity and mortality. Arch Gerontol Geriatr 2010;50:306-10.

18. Chen LY, Liu LK, Liu CL, et al. Predicting functional decline of older men living in veteran homes by minimum data set: implications for disability prevention programs in long term care settings. J Am Med Dir Assoc 2013;14:309.e9-13.

19. Espaulella J, Arnau A, Cubí D, et al. Time-dependent prognostic factors of 6-month mortality in frail elderly patients admitted to post-acute care. Age Ageing 2007;36:407-13.

20. Mühlethaler $\mathrm{R}$, Stuck $\mathrm{AE}$, Minder $\mathrm{CE}$, et al. The prognostic significance of protein-energy malnutrition in geriatric patients. Age Ageing 1995;24:193-7.

21. Sullivan $\mathrm{DH}$, Walls RC. Protein-energy undernutrition and the risk of mortality within six years of hospital discharge. J Am Coll Nutr 1998;17:571-8.

22. Sullivan DH, Bopp MM, Roberson PK. Protein-energy undernutrition and life-threatening complications among the hospitalized elderly. J Gen Intern Med 2002;17:923-32.

23. Liu L, Bopp MM, Roberson PK, et al. Undernutrition and risk of mortality in elderly patients within 1 year of hospital discharge. J Gerontol A Biol Sci Med Sci 2002;57:M741-6.

24. Genton L, Graf CE, Karsegard VL, et al. Low fat-free mass as a marker of mortality in community-dwelling healthy elderly subjects. Age Ageing 2013;42:33-9.

25. Bergman H, Ferrucci L, Guralnik J, et al. Frailty: an emerging research and clinical paradigm -issues and controversies. $J$ Gerontol A Biol Med Sci 2007;62:731.

26. Ferrer $\mathrm{A}$, Badia $\mathrm{T}$, Formiga $\mathrm{F}$, et al. Frailty in the oldest old: prevalence and associated factors. J Am Geriatr Soc 2013;61:294-6.

27. Mezuk B, Edwards L, Lohman M, et al. Depression and frailty in later life: a synthetic review. Int J Geriatr Psychiatry 2012;27:879-92.

28. Inouye SK, Peduzzi PN, Robison JT, et al. Importance of functional measures in predicting mortality among older hospitalized patients. JAMA 1998;279:1187-93.

29. González M, Carrasco M. Delirium: a marker of health status in the geriatric patient. Rev Esp Geriatr Gerontol 2008;43(Suppl 3): 38-41.

30. McCusker J, Cole M, Abrahamowicz M, et al. Delirium predicts 12-month mortality. Arch Intern Med 2002;162:457-63.

31. Cabre M, Serra-Prat M, Palomera E, et al. Prevalence and prognostic implications of dysphagia in elderly patients with pneumonia. Age Ageing 2010;39:39-45.

32. Landi F, Onder G, Russo A, et al. Pressure ulcer and mortality in frail elderly people living in community. Arch Gerontol Geriatr 2007:44:217-23.

33. Gribbin J, Hubbard R, Smith C, et al. Incidence and mortality of falls amongst older people in primary care in the United Kingdom. QJM 2009;102:477-83.

34. Viganò $\mathrm{A}$, Dorgan $\mathrm{M}$, Buckingham $\mathrm{J}$, et al. Survival prediction in terminal cancer patients: a systematic review of the medical literature. Palliat Med 2000;14:363-74.

35. Pesola GR, Ahsan H. Dyspnea as an independent predictor of mortality. Clin Respir J 2014;5:1-11.

36. Figarska SM, Boezen HM, Vonk JM. Dyspnea severity, changes in dyspnea status and mortality in the general population: the Vlagtwedde/Vlaardingen study. Eur J Epidemiol 2012;27:867-76.

37. Watkins LL, Koch GG, Sherwood A, et al. Association of anxiety and depression with all-cause mortality in individuals with coronary heart disease. J Am Heart Assoc 2013;2:e000068.

38. Theou O, Brothers TD, Rockwood MR, et al. Exploring the relationship between national economic indicators and relative fitness and frailty in middle-aged and older Europeans. Age Ageing 2013;42:614-19.

39. Perissinotto CM, Stijacic Cenzer I, Covinsky KE. Loneliness in older persons: a predictor of functional decline and death. Arch Intern Med 2012;172:1078-83.

40. Andrew MK, Mitnitski A, Kirkland SA, et al. The impact of social vulnerability on the survival of the fittest older adults. Age Ageing 2012;41:161-5

41. Smith AKA, Walter LCL, Miao Y, et al. Disability during the last two years of life. JAMA Intern Med 2013;173:1506-13.

42. Zweifel P, Felder S, Meiers M. Ageing of population and health care expenditure: a red herring? Health Econ 1999;8:485-96.

43. Moe J, Kirkland S, Ospina MB, et al. Mortality, admission rates and outpatient use among frequent users of emergency departments: a systematic review. Emerg Med J 2016;33:230-6.

44. Wong ELY, Cheung AWL, Leung MCM, et al. Unplanned readmission rates, length of hospital stay, mortality, and medical costs of ten common medical conditions: a retrospective analysis of Hong Kong hospital data. BMC Health Serv Res 2011;11:149. 
45. Maas T, Murray SA, Engels $\mathrm{Y}$, et al. What tools are available to identify patients with palliative care needs in primary care: a systematic literature review and survey of European practice. $B M J$ Support Palliat Care 2013;3:444-51.

46. The GSF Prognostic Indicator Guidance. 2011. http://www. goldstandardsframework.org.uk/cd-content/uploads/files/General Files/Prognostic Indicator Guidance October 2011.pdf (accessed Jun 2016).

47. Highet G, Crawford D, Murray SA, et al. Development and evaluation of the Supportive and Palliative Care Indicators Too (SPICT): a mixed-methods study. BMJ Support Palliat Care 2014:4:285-90.

48. Thoonsen $B$, Engels $Y$, van Rijswijk $E$, et al. Early identification of palliative care patients in general practice: development of RADboud indicators for PAlliative Care Needs (RADPAC). Br J Gen Pract 2012;62:625-31.

49. Gómez-Batiste X, Martínez-Muñoz M, Blay C, et al. Identifying patients with chronic conditions in need of palliative care in the general population: development of the NECPAL tool and preliminary prevalence rates in Catalonia. BMJ Support Palliat Care 2013;3:300-8.

50. Gómez-Batiste X, Martínez-Muñoz M, Blay C, et al. Identificación de personas con enfermedades crónicas avanzadas y necesidad de atención paliativa en servicios sanitarios y sociales: elaboración del instrumento NECPAL CCOMS-ICOO. Med Clin (Barc) 2013;140:241-5.

51. Gómez-Batiste X, Martínez-Muñoz M, Blay C, et al. Prevalence and characteristics of patients with advanced chronic conditions in need of palliative care in the general population: a cross-sectional study. Palliat Med 2014;28:302-11.

52. Lunney JR, Lynn J, Foley DJ, et al. Patterns of functional decline at the end of life. JAMA 2003;289:2387-92.

53. Murray SA, Kendall M, Boyd K, et al. Illness trajectories and palliative care. BMJ 2005;330:1007-11.

54. Tinetti ME, Fried T. The end of the disease era. Am J Med 2004;116:179-85.

55. von Elm E, Altman DG, Egger M, et al. The Strengthening the Reporting of Observational Studies in Epidemiology (STROBE) statement: guidelines for reporting observational studies. Lancet 2007;370:1453-7.

56. Murray SA, Boyd K. Using the 'surprise question' can identify people with advanced heart failure and COPD who would benefit from a palliative care approach. Palliat Med 2011;25:382

57. Jackson JC, Gordon SM, Hart RP, et al. The association between delirium and cognitive decline: a review of the empirical literature. Neuropsychol Rev 2004; 14:87-98.

58. Boyd KJ, Murray SA. Worsening disability in older people: a trigger for palliative care. BMJ 2015;350:h2439.

59. Gill TM. The central role of prognosis in clinical decision making JAMA 2012;307:199-200.

60. Chen HC, Kodell RL, Cheng KF, et al. Assessment of performance of survival prediction models for cancer prognosis. BMC Med Res Methodol 2012;12:102.

61. Anderson F, Downing GM, Hill J, et al. Palliative Performance Scale (PPS): a new tool. $J$ Palliat Care 1996;12:5-11.

62. Evans $\mathrm{C}, \mathrm{McC}$ arthy $\mathrm{M}$. Prognostic uncertainty in terminal care: can the Karnofsky index help? Lancet 1985;1:1204-6.

63. Wie GA, Cho YA, Kim SY, et al. Prevalence and risk factors of malnutrition among cancer patients according to tumor location and stage in The National Cancer Center in Korea. Nutrition 2010;26:263-8.

64. Pressoir M, Desné S, Berchery D, et al. Prevalence, risk factors and clinical implications of malnutrition in French Comprehensive Cance Centres. Br J Cancer 2010;102:966-71.

65. Aaldriks AA, van der Geest LGM, Giltay EJ, et al. Frailty and malnutrition predictive of mortality risk in older patients with advanced colorectal cancer receiving chemotherapy. J Geriatr Oncol 2013;4:218-26.

66. Datema FR, Ferrier MB, Baatenburg de Jong RJ. Impact of severe malnutrition on short-term mortality and overall survival in head and neck cancer. Oral Oncol 2011;47:910-14.

67. Celli BR, Barnes PJ. Exacerbations of chronic obstructive pulmonary disease. Eur Respir J 2007;29:1224-38.

68. Marchetti N, Criner GJ, Albert RK. Preventing acute exacerbations and hospital admissions in COPD. Chest 2013;143:1444-54.
69. Connors AF, Dawson NV, Thomas C, et al. Outcomes following acute exacerbation of severe chronic obstructive lung disease. The SUPPORT investigators (Study to Understand Prognoses and Preferences for Outcomes and Risks of Treatments). Am J Respir Crit Care Med 1996;154:959-67.

70. Jaagosild P, Dawson NV, Thomas C, et al. Outcomes of acute exacerbation of severe congestive heart failure: quality of life, resource use, and survival. Arch Intern Med 1998;158:1081-9.

71. Liaw YF, Chen JJ, Chen TJ. Acute exacerbation in patients with liver cirrhosis: a clinicopathological study. Liver 1990;10:177-84.

72. Volk ML, Tocco RS, Bazick J, et al. Hospital readmissions among patients with decompensated cirrhosis. Am J Gastroenterol 2012;107:247-52.

73. Donzé J, Lipsitz S, Bates DW, et al. Causes and patterns of readmissions in patients with common comorbidities: retrospective cohort study. BMJ 2013;347:f7171

74. Tsuyuki RT, McKelvie RS, Arnold JM, et al. Acute precipitants of congestive heart failure exacerbations. Arch Intern Med 2001;161:2337-42.

75. Guehne U, Riedel-Heller S, Angermeyer MC. Mortality in dementia: a systematic review. Neuroepidemiology 2005;25:153-62.

76. Brodaty H, Seeher K, Gibson L. Dementia time to death: a systematic literature review on survival time and years of life lost in people with dementia. Int Psychogeriatr 2012;24:1034-45.

77. Kane RL, Shamliyan T, Talley K, et al. The association between geriatric syndromes and survival. J Am Geriatr Soc 2012;60:896-904

78. Gill TM, Gahbauer EA, Han L. Trajectories of disability in the last year of life. N Engl J Med 2010;362:1173-80.

79. Gill TM, Gahbauer EA, Han L, et al. The role of intervening hospital admissions on trajectories of disability in the last year of life: prospective cohort study of older people. BMJ 2015;350:h2361.

80. Sharp T, Moran E, Kuhn I, et al. Do the elderly have a voice? Advance care planning discussions with frail and older individuals: a systematic literature review and narrative synthesis. $\mathrm{Br} J$ Gen Pract 2013;63:657-68.

81. Lynn J. Reliable and sustainable comprehensive care for frail elderly people. JAMA 2013;310:1935-6.

82. British Geriatrics Society. Fit for Frailty. Part 1. 2014. http://www.bgs. org.uk/campaigns/fff/fff2_full.pdf (accessed Jun 2016).

83. Murray SA, Kendall M, Grant E, et al. Patterns of social, psychological, and spiritual decline toward the end of life in lung cancer and heart failure. J Pain Symptom Manage 2007;34:393-402.

84. Evans N, Pasman HR, Donker GA, et al. End-of-life care in general practice: a cross-sectional, retrospective survey of 'cancer', 'organ failure' and 'old-age/dementia' patients. Palliat Med 2014;28: 965-75.

85. Ahmed N, Bestall JC, Ahmedzai SH, et al. Systematic review of the problems and issues of accessing specialist palliative care by patients, carers and health and social care professionals. Palliat Med 2004;18:525-42.

86. Vellas B, Guigoz Y, Garry PJ, et al. The mini nutritional assessment (MNA) and its use in grading the nutritional state of elderly patients. Nutrition 1999;15:116-22.

87. van Kempen JAL, Schers HJ, Philp I, et al. Predictive validity of a two-step tool to map frailty in primary care. BMC Med 2015;13:287.

88. Meier DE. Focusing together on the needs of the sickest $5 \%$, who drive half of all healthcare spending. J Am Geriatr Soc 2014;62:1970-2.

89. Romero-Ortuno R, Kenny RA. The frailty index in Europeans: association with age and mortality. Age Ageing 2012;41:684-9.

90. Drubbel I, de Wit NJ, Bleijenberg N, et al. Prediction of adverse health outcomes in older people using a frailty index based on routine primary care data. J Gerontol A Biol Sci Med Sci 2013;68:301-8.

91. Romero Ortuño R. The Frailty Instrument for primary care of the Survey of Health, Ageing and Retirement in Europe (SHARE-FI): results of the Spanish sample. Rev Esp Geriatr Gerontol 2011;46:243-9.

92. Hoogendijk EO, van der Horst HE, Deeg DJH, et al. The identification of frail older adults in primary care: comparing the accuracy of five simple instruments. Age Ageing 2013;42:262-5.

93. Malmstrom TK, Miller DK, Morley JE. A comparison of four frailty models. J Am Geriatr Soc 2014;62:721-6. 